\title{
KNOWLEDGE MANAGEMENT AND COGNITIVE THEORY: AN AFRICAN CASE STUDY
}

\author{
A Misch \& PKJ Tobin, Gordon Institute of Business Science, University of Pretoria
}

\begin{abstract}
Purpose: The aim of this paper is to report on research into whether knowledge can be managed more effectively by taking into consideration the nature and complexity of information being received by members of an organisation; the cognitive abilities of those members; and finally the nature and composition of the hierarchical structure of the organisation within which those members operate.
\end{abstract}

Design/Methodology/Approach: The research reported on in this paper was carried out using a case study approach, with the focus on a single organisation to which the authors had special access. Data was gathered using a combination of interviews and a focus group, with participants drawn from a cross-section of members of the case study organisation. Analysis was conducted within the framework associated with the primary theoretical model (Jaques \& Clement, 1991) that underpins this research.

Findings: This research helps to further an understanding of how individual and organisational performance may be influenced by issues such as cognitive processes and the relationship to information complexity. The research findings support the work of Jaques and Clement (1991).

Implications: This research had important implications for the organisation in the case study investigation. Other organisations would need to evaluate the research findings in terms of their applicability to other organisations in the same industry, in the same country (South Africa) or elsewhere in other industries or in other countries on the African continent.

Originality/Value: This research is original in terms of the application of cognitive theory in conjunction with knowledge management principles in the context of the legal profession in South Africa. It has potential value in many other industries and countries.

Key words and phrases: case study, cognitive theory, knowledge management, law firms, organisational structure.

\section{INTRODUCTION}

Africa: A continent of more than 50 individual nation states, over 800 million inhabitants and a wide variety of languages, cultures and traditions, and a continent which faces both significant challenges and opportunities. Through a variety of national, regional, and continent-wide initiatives, stakeholders across the border are looking for ways to contribute to the creation and maintenance of sustainable economic growth (Cockett, 2006). One component of the possible solution to the issue of sustainable economic development may lie in a clear understanding of the context within which organisations perform, with specific relevance to the way in which knowledge is managed. The focus on knowledge management as a contributor to organisational success has many aspects. This research was focused on investigating a particular theoretical concept and applying it to an organisation, using a case study methodology. This research sought to introduce a new dimension to knowledge management that takes cognisance not only of traditional technocratic, economic and behavioural approaches to knowledge management, but also introduces an awareness of how cognitive abilities of knowledge workers and organisational structures impact on an organisation's ability to harness knowledge in the quest for sustainable competitive advantage. This has important implications for the ability of organisations across the African continent, whether large or small, whether in the public or private sector, to be able to contribute to the goal of sustainable economic growth.

Cognitive theory has its origins in the discipline of psychology, with its early foundation being laid by behavioural and social psychologists. Broadly, the theory holds that people's perceptions, their feelings, thinking and their actions result to a significant extent from processes, which go beyond the simple input provided by the senses (since pre-existing mental models, for instance, are a way of 'ordering' the world and are therefore projected onto the world as it is perceived through the senses). 
Many of these mental models find their origins in the very earliest stages of development, including many of the games played in childhood (many if not all of which are culturally patterned). Games provide opportunities to imitate others and in the process generate opportunities for intellectual development. Initially, these games may be recollections and re-enactments of real situations, but through imagination and the recognition of implicit rules governing the activities, children begin to achieve an elementary mastery of abstract thought and what has been referred to as the 'inner speech' which may be the foundation for all higher levels of functioning (Hanfmann, Vakar \& Vygotsky, 1962:10). In this sense, cognitive theory may provide an essential link between environmental factors and behaviour and provides one explanation of why similar sensory inputs may lead to completely different behaviour in different people. A particular aspect of cognitive theory, that proposed by Jaques and Clement (1991), was used in this research and is discussed in more detail later in this paper.

This paper states the purpose of the research, then outlines the problem to be investigated and the relevant literature as background. The research methodology and the findings and their analysis then lead to a statement of the implications and value of the research with a brief conclusion to the paper.

\section{PURPOSE OF THE RESEARCH}

This research was designed to explore a dimension of knowledge management that takes cognisance of the need for an awareness of how cognitive abilities of knowledge workers and organisational structures impact on an organisation's ability to harness knowledge in the quest for sustainable competitive advantage. The aim of the research was to investigate how different people within an organisation may process the same information in different ways. The classification system used to analyse the participants' cognitive processes was that proposed by Jacques and Clement (1991), comprising four distinct cognitive processes and four levels of information complexity, ranging from the concrete through to the third level of abstraction.

The aim of the research was not to derive accurate profiles of the cognitive abilities of individual participants in the investigation. Such a task would have gone well beyond the scope and purpose of this research and the skills and qualifications of the authors. Rather, the aim was to observe cognitive processes being applied in practice, in a particular South African business, but with potential implications more broadly across business.

\section{BACKGROUND TO THE STUDY}

In South Africa, knowledge management has been the focus of a number of research projects (Botha, 2004; Botha \& Fouché, 2002; Davel \& Snyman, 2005; Du Plessis \& Du Toit, 2005; Kok, 2003; Kruger \& Snyman, 2005a; Kruger \& Snyman, 2005b; Ndlela \& Du Toit, 2000; Tobin \& Franze, 2005; Tobin \& Snyman, 2004; Tobin \& Volavsek, 2006 and Van den Berg \& Snyman, 2003). Of these, only one study, was concerned with KM in SA law firms (Du Plessis \& Du Toit, 2005), and this had a narrow focus on the legal research process, hence it was felt that the present research would be of value in understanding the application of the work of Jaques and Clement (1991).

Organisations continuously struggle to define their sustainable competitive advantage in the marketplace while remaining flexible and responsive (Drucker, 1995). This is as true for many organisations across the African continent today as when Drucker made his original observation from an American perspective a decade ago. Employees are becoming ever more highly educated and mobile, as they increasingly carry the means of production around with them in their heads and there has been a shift in focus to the internal resources and capabilities of organisations as a key determinant of competitive advantage (Barney, 1991 and Lank, 1997). This also applies to those working in African businesses, large and small. Information and knowledge have become increasingly recognised as competitive differentiators (Barnes, 2002), particularly because knowledge-based resources are socially complex and are therefore difficult both to understand and to imitate by others (Alavi \& Leidner, 2001). Operational routines, skills and know-how have come to be acknowledged as the most valuable organisational assets (Spencer, 1996) and knowledge management was born out of the recognition that it was possible to manage these assets strategically (Grant, 1991 and Tobin \& Franze, 2005). 
Knowledge has been recognised as the driver of productivity and economic growth (OECD, 1996) and as a significant source of economic value (Huseman \& Goodman, 1999; Rumizen, 2002 and Tobin \& Snyman, 2004). Knowledge management projects attempt to harness some of this intellectual property to create tangible value, but may fail to live up to management expectations in the sense that they do not deliver (or at least appear not to deliver) tangible improvements in productivity, profitability and sustainable competitive advantage over competing businesses, particularly where information technology is concerned (Bryan, 2004). Large numbers of knowledge management projects continue to fail (Storey \& Barnett, 2000), although the data in this respect for African businesses is much less complete (Botha, 2004 and Tobin \& Volavsek, 2006), particularly for law firms. In contrast, there have been a number of international studies focusing on law firms in the context of knowledge management (Kay, 2003 and Khandelwal \& Gottschalk, 2003)

To date, many of the theoretical approaches to knowledge management appear to have largely neglected to differentiate between various levels of information (and knowledge) complexity, and appear to have failed to bring into reckoning the cognitive processes applied by individuals as they process information. This has led some to view knowledge management simply as those processes that capture and store accumulated knowledge for later use: "If knowledge is captured properly once with specific technology, this knowledge can be set aside to address the needs of the organisation," (Lawson, 2000:14). Another problem that has been identified with existing knowledge management approaches lies in the difficulty of developing suitable metrics to measure the contribution of Knowledge Management (as a discipline) or specific knowledge management initiatives to an organisation's bottom line (Domingues, Laverde, Lisarralde \& Arregui, 2003 and Rumizen, 2002). Knowledge itself is particularly hard to quantify or to price (OECD, 1996). Another problem lies in the fact that there appears to exist little consensus amongst knowledge management practitioners and amongst executives on the meaning and relevance of knowledge to specific organisations and of the purposes that knowledge management initiatives should achieve (Domingues et al., 2003; Huseman \& Goodman, 1999 and Rumizen 2002). A further problem with existing knowledge management approaches relates to the fact that they do not seem to take into account the effect in different persons of their different cognitive abilities, and the effects of this on the utility of conventional knowledge management systems.

One answer to these issues may be found in cognitive theory. Meaning and understanding are created by the interpretation of the person receiving that information, bringing to bear personal experiences, views and insights (Intronas, 1992). Barlow (2001) expresses a similar idea when he suggests that it is often the perspective adopted by persons when trying to solve problems that create complexity. It is the existence of mental models and of filtering techniques that will determine what each individual person is able to perceive and what each person filters out of their sensory registers, their short-term memory store and their long-term memory store (Atkinson \& Shiffrin, 1968).

Cognitive theory has its origins in the discipline of psychology. Broadly speaking, the theory holds that people's perceptions, their feelings, their thinking and their actions result to a significant extent from processes, which go beyond the simple input provided by the senses (since pre-existing mental models, for instance, are a way of ordering the world and are therefore projected onto the world as it is perceived through the senses). Cognitive theory provides the link between environmental factors and behaviour and provides one explanation why similar sensory inputs may lead to completely different behavioural output in different people. Cognitive complexity refers to information that is neither well defined nor internally consistent. Barlow (2001) distinguishes this cognitive complexity from problems or systems that are complicated. Barlow believes that very few people excel at both complicated tasks and those that are cognitively complex.

Of particular interest in the area of cognitive complexity is Stratified Systems Theory (Jacques \& Clement, 1991), which differentiates between different levels of information complexity, and different types of cognitive processes that individuals apply to process information. Jaques further suggests that hierarchies within organisations should be designed in such a way that each higher level of authority within the hierarchical organisation is required to process information at the next higher level of cognitive processing ability than the previous level. This view is of interest to organisations across the African continent, many of which have yet to evolve from the traditional hierarchical model inherited from the former colonial powers, in their efforts to create sustainable economic growth. Stratified Systems Theory (Jacques \& Clement, 1991) is based on the view that there are four distinct 
types of cognitive processes that people are able to employ to manage and organise information. These are:

- Assertive processing - in which information is organised in the form of direct associations and assertions relevant to the immediate situation.

- Cumulative processing - in which reasoning takes place by the accumulation of pieces of information that may be relevant to any given situation and organising them in relation to each other, so as to allow the person to reach a conclusion.

- Serial processing - allows persons to assemble information in a linear form into a logical sequence, providing a series of events connected over time in cause and effect relationships and possible future consequences.

- Parallel processing - which takes place when information is organised into a number of distinct serial processes in parallel with one another and relationships between the processes are created as processes within each series impact on processes in other series.

The development of an individual's cognitive processes does not proceed incrementally and these processes do not blend into one another: rather the development proceeds in a series of discontinuous steps, from one distinct cognitive process to the next (Jacques \& Clement, 1991). There are also four orders of information complexity. These orders of increasing information complexity include:

- The first order of complexity, concrete objects. This relates to the thousands of the actual individual and distinct physical tasks people execute every day.

- The second order of complexity (the first level of abstraction), verbal information used in everyday ordinary language. At this level, people deal with symbols used to describe the chunks of concrete processes referred to.

- The third order of complexity (the second order of abstraction) refers to second order processes being grouped into more complex conceptual orders (to describe the conceptual world of the corporation, for example). These concepts are often ambiguous, dynamic and inextricably interrelated.

- The fourth order of complexity (the third level of abstraction) is that in which third order concepts are combined into universal ideas and language required for handling broader tasks, such as governing a society with the use of ideologies or philosophies.

Numerals 1 to 4 were assigned to the four cognitive processes, whilst letters $A$ to $D$ were assigned to the four levels of abstraction. The four orders of information complexity represent increasingly complex concepts, which people need absorb and process by using the cognitive processes at their disposal in order to solve problems and complete the tasks facing them. Each person has a distinct limit to his/her cognitive power (which refers to the maximum number of variables each person is able to deal with appropriately at any one moment in time, or the maximum amount of information a person is able to process within a given period of time). As people grow and mature over their lifetime, their cognitive abilities move, step-by-step, from less complex cognitive processes to more complex cognitive processes within specific orders of information complexity, before moving through the same sequence of steps at the next higher level of information complexity (Jaques \& Clement, 1991).

\section{PROBLEM INVESTIGATED}

Jaques and Clement's (1991) theory suggests an entirely new approach to the manner in which knowledge is generated and processed by and within organisations. This approach recognises that the same elements of information entering an organisation at different levels of the organisational hierarchy (and which are therefore received by different individuals within the organisation) will be processed in different ways and will generate different knowledge. This will lead to different decisions being taken and actions initiated in response to the same information being received. In turn, this 
suggests that attempts to capture the knowledge created by those individuals by reducing it to data that is capable of being stored in databases or other information depositories for later use may be a futile exercise, as future recipients of this information and data will interpret it using their own cognitive abilities. These concepts have great value to organisations in the rapidly developing African economies where deployment of technology-based solutions may be less preferable to knowledge solutions which recognise and leverage existing social norms and traditions.

This issue could also be one explanation of why many Knowledge Management initiatives fail: the information (or knowledge) being stored does not convey the same meaning, and does not have the same relevance to subsequent recipients of this information, as it did to the original creators of the information. This may lead to an indiscriminate build-up of information and knowledge in data and information capturing systems, the meaning and relevance of which (when taken out of the context in which it was originally stored) will be lost to persons not familiar with the original context and relevance. As African businesses seek to grow, and as a consequence become more complex in their size and operations, an understanding of this issue may help to unleash the potential for further economic growth.

One conclusion might be that organisations should focus less on attempts to capture knowledge, and more on knowledge flows and the processes used to ensure that the right elements of information are received at the appropriate levels of the organisation, at the right time, to ensure that knowledge workers are enabled to take effective, timely and, where appropriate, innovative action. Knowledge management then becomes a matter of ensuring that those same individuals have the requisite cognitive processing abilities required by their position within the organisational hierarchy. This requires ensuring that the organisational hierarchy is structured appropriately to allow information to be received and knowledge to be created and shared freely in order to further the aims of the organisation and to create tangible value for the organisation. In order to relate the work of Jacques and Clement (1991) outlined above to a live situation in a business in contemporary South Africa, an investigation was carried out within an established company operating in a knowledge-intensive service industry. A qualitative case study was designed in order to investigate the following:

Whether different persons within the organisation process the same information presented to them in different ways; and, if so,

- Determining whether the results from this investigation could be aligned to the classifications of cognitive processes proposed by Jaques and Clement (1991);

- Drawing conclusions from these results for the organisational design and the processes designed to create knowledge within that organisation; and

- Demonstrating that the same information can be processed into knowledge that is relevant to the organisation at various levels in the organisational hierarchy.

This research project was therefore conceptualised to explore, within the context of knowledge management, how cognitive abilities of knowledge workers and organisational structures impact on an organisation's ability to harness knowledge in the quest for sustainable competitive advantage. The aim of the research was to investigate how different people within an organisation may process the same information in different ways. The principal purpose of the analysis of the research was to gather evidence of any of the four cognitive processes identified by Jaques and Clement (1991) being applied by the respondents. The secondary purpose of the analysis was to gather evidence of the use of different levels of abstraction in the argumentation employed by the respondents.

\section{RESEARCH METHODOLOGY}

The case study organisation selection occurred on the basis of freedom of access to all levels of the business (one of the co-authors being a member of the organisation themselves); and on the basis of the relevance of the organisation and its processes to the research problem. Knowledge, as well as its innovative creation and the ability to exploit this knowledge, had been identified by the organisation as one of the key drivers of a sustainable competitive advantage over its competitors, enhancing the suitability of the selection of this particular organisation to meeting the goals of the current research. 
The research conducted was based on a case study methodology, in which one of the co-authors became a participant observer. The unit of analysis was the population of the members of the professional staff of this specific organisation, operating in a knowledge-intensive service industry in Johannesburg, South Africa. Representatives from three distinct hierarchical levels were researched: senior management, senior professional staff, and junior professional staff. The chosen respondents represented a stratified random probability sample: a total of nine respondents were selected - three respondents each were selected from each of the three hierarchical levels of the organisation referred to here. The choice of respondents within each hierarchical level was made entirely at random and fell on the first three members of each group arriving at work on a specific day (with the one exception of the junior professional staff, of which there are only three in the organisation). It was coincidental that the distribution of men and women in the investigation sample was highly correlated with the distribution of men and women amongst senior management, senior and junior professional staff (namely 55\% men and $45 \%$ women). It was also coincidental that the respondents represented all three of the organisation's functional business units. All respondents were asked to participate as volunteers, and were assured of absolute anonymity in the documentation and publication of the research findings.

In order to obtain evidence of different cognitive processes, it was decided to facilitate a group discussion by the respondents on the topic of euthanasia. The purpose of the group discussion was to engage the respondents in a topic, to which they would be able to commit to both emotionally and intellectually, in order to allow them to perform at the highest possible level of their cognitive abilities. Euthanasia was also a subject that was used by Jaques and Clement (1991) to practically illustrate how people with specific cognitive ability profiles have argued on this topic. The type of argumentation used for illustrative purposes by Jaques and Clement (1991) (as opposed to the actual arguments used in the investigation described in this research) was used as a type of blueprint to facilitate the recognition of evidence of specific cognitive problem-solving behaviour. The group discussion on euthanasia by the respondents in this case study was facilitated by one of the co-authors and observed by an independent outside observer. The group discussion was also tape-recorded for later transcription. The topic was made known to the respondents two days prior to the group discussion taking place, to allow respondents to prepare themselves. It was felt that respondents would be able to engage more actively in the debate if they felt comfortable that they would be able to back up their arguments with such facts, figures, quotations, anecdotal evidence, or other discussion tools that they might choose to use; than if the debate would have had to have been carried out on an unprepared, and possibly purely emotional, reaction-driven level.

In the second phase of the investigation, respondents were individually presented with quotations of statements made by representatives of a number of corporate clients of the organisation. Respondents were asked to share how they interpreted these statements, to remark on the implications of these statements for themselves, as well as for the company and industry practices, and to offer any other open-ended responses they felt to be relevant. The principal purpose of these interviews was to establish evidence of the use of any or all of Jaques and Clement's (1991) four levels of abstraction and to cross-reference the results of the group discussion. The client statements used contained information that was essentially non-technical in nature (in the sense that this information did not relate to specific technical questions that the client might have had at the time). Rather, they related to client-specific needs and wants, and thus constituted a form of market intelligence on those clients and information that could be translated directly into concrete actions, as well as into conceptual issues.

Using this information, it was intended to:

- Ascertain whether respondents would deal with the issues raised at a similar cognitive level as they had treated the topic of euthanasia during the group discussion; and

- Demonstrate the effect that this would have on the responses that respondents gave to the information provided to them by way of the clients' statements

The intention was then to use these results to explore whether the same information presented to different respondents would be processed in different ways, thus leading to potentially different sets of actions, processes and activities. 
Data collection occurred in two phases. During phase 1, one of the co-authors became a participant observer during a group discussion held by the respondents. This group discussion was facilitated by one of the co-authors and was monitored by an independent observer, who was familiar with the work of Jaques and Clement (1991) and who has been recognised by her peers as an expert in the assessment of cognitive abilities. During phase 2, one of the co-authors conducted individual interviews with the respondents, using a structured questionnaire, with the opportunity for additional unstructured responses. The data reduction and analysis was qualitative only and based on a content analysis of the contributions made by each respondent during the group discussion and their responses provided to the questionnaires and further discussion during the individual interviews.

The subsequent transcripts of the two phases were rearranged in such a way as to bring all contributions by each respondent under one heading. This was done in order to allow an overall view of each respondent's contribution to the discussion to be obtained. Respondents were allocated random numbers ( $R 1$ to $R 9$ ) to mask their identities. These contributions ranged from almost no contribution made at all by respondent R7, to lengthy arguments presented by respondent R3.

For purposes of the analysis of the arguments used by the respondents, a template was prepared from the examples provided by the authors Jaques and Clement (1991) of how persons applying different cognitive processes at specific levels of abstraction might argue the case for or against the topic under discussion (namely the case for and against euthanasia).

The analysis of both the group discussion and the structured interviews was based on the transcripts prepared from the tape recordings of these two phases of the investigation, the contemporaneous notes that were prepared by one of the co-authors, and, in the case of the analysis of the group discussion, on the basis of the notes and observations of the independent observer, whose input was used to verify and augment the observations. The results of the group discussion and of the structured interviews were categorised in accordance with the classifications of cognitive processes and levels of abstraction identified by Jaques and Clement (1991), where letters A to D refer to the four levels of abstraction and numerals 1 to 4 refer to the four cognitive processes.

\section{FINDINGS}

The findings of the case study gave a clear indication of the application by respondents of different cognitive processes and of the use of different levels of abstraction identified by Jaques and Clement (1991). Although the findings do not allow conclusions to be drawn about the specific personal cognitive abilities of the respondents, there was evidence, however, that application of different cognitive processes at varying levels of abstraction by the respondents led to clearly differing responses. From the outset, it became clear that not all respondents engaged in the discussion spontaneously and, even when prompted, did not commit to the discussion sufficiently to have allowed an assessment of that respondent's cognitive abilities. However, the purpose of this research was not an assessment of any of the respondents' cognitive abilities, rather there was an attempt to classify the responses according to Jaques and Clement's (1991) levels of abstraction and cognitive categories. This article demonstrates that the research objective was supported by the empirical data. As an overall observation, it was found noteworthy that, despite the fact that respondents (such as respondent 3 , for instance) conducted the discussion in terms of more fundamental principles and concepts (i.e. at a higher level of abstraction than other respondents), respondents that started off by presenting their arguments in more concrete terms (as did respondents 1 and 2, for instance) did not rise to the challenge of engaging respondent 3 at that (higher) level, but remained firmly rooted in their own 'category of abstraction'.

\section{Analysis of Group Discussion}

Respondent R1 displayed clear elements of category B2 argumentation, in which arguments are supported by accumulated data, and that respondent would state his/her views by bringing one or several supportive reasons to bear. Respondent R1 chose to present the arguments for the purposes of this discussion in a manner that addressed a number of issues, such as: the manner of inducing death; the processes that could be used to administer the decision-making processes and safeguard the rights of the persons involved; and citing suffering (or the alleviation thereof) as the overarching reason for supporting the practice of euthanasia. In response to propositions such as the question of 
whether the practice would reduce humans to economic commodities (which indicates category ' $C$ ' thought, at the second level of abstraction), respondent R1 replied by bringing the discussion back to the first level of abstraction on two occasions: once by reference to the fact that a person choosing to die was making that decision for him/herself, and once by providing a concrete example of how a person would continue to suffer without the benefit of being able to choose death.

Respondent R1 also made direct associations with concrete problems, which is almost assertive (cognitive process ' 1 '): "the person is suffering, therefore let us induce death to end the suffering". However, this respondent did so in a number of respects by accumulating related concrete problems and solving them in a similar fashion. The respondent reasoned by accumulating possibly significant pieces of information and organising them in relation to each other so as to be able to reach a conclusion (to use the description of Jaques and Clement's cognitive process ' 2 ').

A similar method of argumentation was employed by respondent R8, who accumulated arguments referring to freedom of religion, the right to dignity, the free will involved in bringing about one's own death and the right to life (phrased in terms of a choice not to exercise one's right to life). While the rights to dignity and to life might be construed to indicate thought at a more conceptual level, (possibly indicative of argumentation at the conceptual level, being the second level of abstraction, or category ' $C$ '), analysis showed that the references in respondent R8's contribution were references to constitutional rights (as guaranteed by the South African Constitution), which are beginning to be given a definitive content by the judgments of the constitutional courts. A right to life based on considerations of 'the primacy of life' would therefore have a much wider content than a right to life based on a constitutional principle. As such, it appeared that this respondent was applying cumulative processes (process 2) at the second level of abstraction (level 'B').

Respondent R2 structured an argument based on an analogy with abortion, stating that the practice of abortion had paved the way for euthanasia, as the decisions involved in euthanasia were already, in effect, being taken on a daily basis, which were informed decisions with safeguards and restrictions. The arguments used were therefore built as a logical series of events (indicative of serial processing) but not based on conceptual foundations that would have been indicative of level ' $C$ ' abstraction, but rather based on the foundation of existing legal processes designed to safeguard the rights of unborn children and their mothers (which was indicative of level 'B' abstraction).

Respondent R9 relied on the argument formulated on the 'gift of life', a concept distinct from the concept of treating humans as mere 'commodities' in the sense of being objects that should be disposed of if the cost of keeping them alive should exceed the productive benefit that they are able to provide. Merely pointing out the threat that humans could be seen as commodities if euthanasia was permitted to be practiced, did not in itself provide an indication of thinking at the second level of abstraction. However, the reference and reliance on 'the gift of life' to support the argument suggested that this respondent's thinking was informed by more than a mere use of symbols to describe concrete problems, dangers and solutions (as was the case with respondent R1's "we have a way to end suffering humanely" argument). This argument must (from the context) have been informed by (however insufficiently articulated) an understanding that the value of life is greater than any costs associated with keeping a terminally ill patient alive for extended periods of time. The use of the analogy of prisoners serving a life term in jail and the problems pointed out with regards to where to draw the line between 'insanity', 'stupidity', 'illness', 'terminal illness' (and the reference to Christopher Reeve's inability to terminate his life while being kept alive by a machine) all pointed to the possibility of cumulative processing being brought to bear on the question.

Respondent R6 pointed to concepts such as: societal values (such as the value of caring for fragile people and others who may need protection, and the value of ensuring that people within society are not permitted to make frivolous choices in instances in which the consequences of those choices are final and irreversible); the dangers inherent in the process of legalising euthanasia, which may lead to a possible loss of objectivity; the question of the impact of morality on the debate; and the role and duties of government in society in relation to people that may wish to choose death. These arguments were not, however, formulated into a serial argument, but were merely presented as a selection of a number of arguments that could have been advanced, and therefore probably represent evidence of cumulative processing. 
There was some evidence of respondent R3 engaging in the discussion at a cognitive ability at the level of the Jaques and Clement (1991) category C3 (by presenting conceptual arguments organised as conceptualised alternative sequences, leading to alternative strategies). This respondent also raised the issue of societal values (and in particular the issue of the value that holds killing life to be wrong) as well as underpinning the argument with reference to moral, religious, constitutional and other legal aspects. Respondent R3 then proceeded to lay the foundation for the argument by drawing a distinction between assisted suicide and euthanasia and using examples for each, as well as illustrating the argument with certain policies being applied in state hospitals on the allocation of resources and then rounding off the argument by concluding that there was a basic choice to be made between the moral point of view (with its consequences) and the point of view that saw humans as generators and consumers of economic value (and its consequences). The two choices were not related to each other and therefore could not have been considered to have fallen into the parallel processing framework (cognitive process ' 4 '), but there were strong indicators of sequential (serial) processing (cognitive process ' 3 ') while using second order of complexity concepts (level of abstraction ' $C$ ').

\section{Analysis of Personal Interviews}

The group discussion was followed by individual interviews. All respondents (who had participated in the group discussion) were asked to comment, in an open-ended manner, on seven identical statements. These included, under the heading of each of the statements, an illustration of what comments the respondents could have made on the first (symbolic) level of abstraction, and what responses might have been given, on the second (conceptual) level of abstraction. Individual responses were tape-recorded and later transcribed. Generally, the results indicated that respondents processed the statements given at much the same levels of abstraction as they argued the question of euthanasia during the group discussion. There were two exceptions: respondent R5 (a relatively junior member of staff, not in a managerial position), in addressing the statements that "[service providers] were required to be pro-active in dealing with matters", and that "the relationship between [service providers] and their clients was one of trust", related these statements to the role of [service providers] within society generally. In subsequent questions, the same respondent tied in this relationship between [service providers] generally and society as a whole with some practical implications that this had for the business of being a [service provider] [whose answers provided] - a strong indication that respondent R5 was certainly capable of processing information at the second level of (conceptual) abstraction - the Jaques and Clement (1991) level ' $C$ '.

Respondent R6, on the other hand, (a respondent in a senior managerial position) appeared to respond to all seven statements put to him on a purely symbolic level (the 1st level of abstraction). In contrast, the other two respondents at managerial level (respondents R3 and R9) appeared to relate the statements much more to the conceptual issues underpinning these statements. Respondent R9, for instance, related the first statement to the need to set up processes to ensure efficient operational execution, the need to determine staff training needs and IT system requirements, and concluded that the statement meant that there would be continued downward pressure on fees; the organisation's service offerings increasingly being treated as a commodity rather than a specialised service. Respondent R6, on the other hand, responded to the same statement by describing (in 'symbolic' terms) the operational implications of this statement for this respondent's specific sphere of operations. The same pattern of responses were observed for respondent R6 for the other statements, while respondents R3 and R9 consistently appeared to relate the statements put to them to more conceptual ideas before distilling from these conclusions about the practical implications for the organisation or specific departments.

\section{Concluding Remarks}

It is interesting to note that respondents $\mathrm{R} 1, \mathrm{R} 4, \mathrm{R} 5, \mathrm{R} 7$, and $\mathrm{R} 8$ (all of whom displayed a propensity to conduct the discussion at the level of category 'B2' reasoning) all represented the most junior members of staff that participated in this experiment, while all members of management present tackled the topic at the second level of abstraction (category ' $C$ ' reasoning), with the most senior member of staff present providing indications of possibly having the highest cognitive abilities of the group. The most senior member of the junior staff (respondent R2) addressed the topic at the level of B3 argumentation. It is possible, therefore, to conclude that this represented clear evidence in support 
of the Jaques and Clement (1991) theory on cognitive abilities and cognitive processes at various levels of the hierarchy of an organisation. It should be noted, though, that this research was not designed to minimise extraneous factors that might very likely have influenced the results. Respondent R5's employment at the organisation, for example, had only commenced a week earlier. This respondent may not have felt sufficiently comfortable to engage vigorously in a controversial debate - particularly as a member of a racial minority in the context of the composition of this particular organisation. Other personal factors, such as a natural disinclination to speak in public (such as was observed in respondent 7), would also have had a major impact. Another influencing factor in the evaluation of the results of this data would include the power relationships existing between all of the participants to the discussion.

What can be concluded, though, is that the data has shown clear evidence of the possibility of categorising arguments in accordance with the four levels of abstraction and the four levels of cognitive abilities suggested by Jaques and Clement (1991), and that people's propensities to repeatedly conduct discussions and to execute their work tasks at these levels may be an indicator of their cognitive abilities. The results also show that different individuals will take the same information presented to them and convert this into different knowledge, which leads to different action sets, which may even be counter-productive to one another or to the overall business strategy of the organisation or of individual departments. The fact that the use of differing cognitive processes at different levels of abstraction led to the creation of different knowledge from the same set of information (i.e. the statements presented to them during the individual interviews) and thus to different action sets, leads to the conclusions presented in the next section. It is also recognised that the volume of data gathered during this case study was somewhat limited, due to the overall constraints under which the research project was conducted. However, rigour was applied in the application of the research methodology, in particular through the use of an independent observer, to reduce the possibility of bias and subjectivity through the participant-observer status of one of the coauthor's. It is also recognised, that future research projects which seek to apply the principles of the work of Jaques and Clement (1991) may be structured in such a way that the limitations of the current research project may be at least, in part, overcome.

\section{IMPLICATIONS OF THE RESEARCH}

The implications of this research project may be applied at a number of levels. First, in the case of the individual organisation that participated in the case study. Second, for other organisations who seek to improve their understanding of the role and importance of the management of knowledge as a contributor to enhance organisational performance, and therefore to overall sustainable economic growth. Of particular interest, is that this research was conducted in South Africa, and may therefore provide a useful starting point for other organisations in the same country or across the continent as a whole, in seeking to improve their understanding of how to leverage the work of Jaques and Clement (1991) as well as the findings of this specific research project. The approach of Jaques and Clement (1991) suggests that the larger the range of interaction of knowledge workers within an organisation, (with the least amount of formal hierarchical or vertically boundaries and obstacles) the more knowledge will flow within the organisation and the more effective such knowledge flows will be. Other ways of achieving a similar effect would be:

- The use of a matrix -type structure in the organisation design,

- The use of process-based structures, including the use of multi-disciplinary teams; and

- The use of network-based structures.

This current research does not advocate the radical de-layering of organisational structures, or the removal of all formal structures and hierarchies altogether. However, this research does recognise that Jaques and Clement (1991) suggest that the structure of an enterprise determines roles and functions and the relationships between these roles and functions. In this sense, hierarchical layering does not only provide structure, but also meaning. Those authors believe that successive layers should represent successive categories of task complexity and cognitive ability. This allows managers in the next higher hierarchical layer to exercise their vested authority, to provide direction and set contexts. Rumizen (2002) suggests that the internal structures within an organisation represent the organisational capabilities to meet customer requirements and that it is these structures that make available to others what one person knows. A certain number of hierarchical layers (determined by the 
nature and complexity of the tasks to be executed) is therefore an essential feature in organisational design, and one that supports knowledge flows and productivity through the creation of responsibilities, accountability, respect, motivation and direction. The existence of too many layers in the hierarchical structure of an organisation (or the existence of hierarchical layers not structured according to the information complexity of the tasks to be performed at that level and the cognitive abilities required at that level), on the other hand, would be one certain way of ensuring that information is either lost within the structure or is only accessible by bypassing formal reporting structures.

One unanticipated (though positive) result of breaking organisations out of the traditional functionally arranged vertical (silo) structures and one possible explanation for the success of many of these new approaches to organisational design, may be the opportunities that these structures offer their members to approach problems through techniques such as reframing and decentring, described by Perkins (2001), as two of the key elements that contribute to the art of breakthrough thinking. Reframing in this sense refers to the ability to recognise assumptions that are limiting the search for an answer and looking at the problem in a different context. Decentring (as used by Perkins) refers to the ability to let go of a position currently being held and which, more likely than not, is limiting the ability to rove more freely.

\section{VALUE OF THE RESEARCH}

For the organisation that participated in the investigation described in this research, these research findings have found a practical and tangible application. It was decided to create a centre (to be known as the Business and Strategy Development Unit) charged with, amongst other responsibilities: the co-ordination of critical knowledge flows, strategies and operational activities; encouraging improved interaction of members of staff at similar hierarchical levels across functional company structures; and reviewing existing process designs to ensure a match between task complexities and hierarchical levels within the organisation. One of the ways in which this centre could achieve its mandated functions, for instance, was to ensure that the marketing function ceased to be a function reserved for senior management but become a function of all members of staff at all levels of the corporate hierarchy. Assigning specific marketing functions to members of staff, while ensuring that all staff understood the function of those tasks in the context of the wider marketing strategy of the organisation, ensured that marketing became the first function in respect of which members were able to look across the functional structures of the organisation, to recognise the meaning and importance of their specific tasks within the broader context.

This re-invigorated the marketing efforts of the organisation through the generation of innovative and focussed marketing approaches. At the same time, this approach allowed staff access to marketing knowledge beyond the confines of specific functional company structures from people at similar hierarchical (and thus cognitive) levels, which in turn enhanced their abilities to understand and interpret the information provided in context, while encouraging processes of decentring and reframing. Beyond the marketing function, a number of other functions that lend themselves to similar cross-functional approaches were identified, including: compliance issues, strategy implementation, and the harvesting of industry intelligence and client information (particularly where clients are shared across functional divisions). Another way in which these research findings were applied was through the creation of a new management committee consisting of two partners, four senior associates and two senior managers of the organisation. This structure allowed members of different operational units at different levels of the organisation to interact, create and share knowledge and cross-fertilise ideas.

The initiative described here is one designed specifically to meet the perceived needs of this particular organisation, operating within a specific industry at a specific time. It is not intended to represent a generic application of the research findings to commercial enterprises in South Africa generally. The implications of the research findings will differ from industry to industry and organisation to organisation. Nevertheless, it is believed that the research findings have a wide relevance to African business across the continent, particularly in knowledge intensive industries in which organisations typically have a number of hierarchical layers while being structured into a number of functional divisions. The relevance of this approach to African companies lies in the recognition that knowledge management includes corporate structuring, corporate process design 
and matching, not only the technical abilities, but also the cognitive processing abilities of individuals to the positions to be filled by them.

\section{CONCLUSION}

The authors of this paper believe that the research findings set out in this paper provide a basis for the conclusion that the application of the theories of Jaques and Clement (1991) in respect of information complexity, cognitive abilities and the implications thereof on organisational structuring, add a valuable dimension to the practice of managing organisational knowledge and, ultimately, the creation of more profitable and more competitive businesses. These findings are also particularly relevant in a country such as South Africa (and potentially more broadly across the African continent), in which racial, cultural and language barriers often obscure real potential and real shortcomings by providing more objective measures of ability that cut across culturally based assessment models and frameworks.

\section{REFERENCES}

Alavi M \& Leidner DE. 2001. Knowledge Management and Knowledge Management systems: conceptual foundations and research issues. MIS Quarterly, 25(1):107-136.

Atkinson R \& Shiffrin R. 1968. Human memory: a proposed system and its control processes. In Spence \& Spence, (Eds.). The psychology of learning and motivation: advances in research and theory (Vol.2). New York: Academic Press.

Barlow CM. 2001. Exploring a human centred perspective on collaboration and knowledge management systems. Illinois: Illinois Institute of Technology, Stuart Graduate School of Business.

Barney J. 1991. Firm resources and sustained competitive advantage. Journal of Management, 17: 99-120.

Barnes S. 2002. Knowledge Management systems - theory and practice. London: Thomson Learning.

Botha DF. 2004. Towards an instrument for surveying knowledge management practices. South African Journal of Business Management, 36(1):1-6.

Botha DF \& Fouché B. 2002. Knowledge management practices in the South African business sector: preliminary findings of a longitudinal study. South African Journal of Business Management, 33(2):13-19.

Bryan LL. 2004. Making a market in knowledge. The McKinsey Quarterly, 40(3):101-111.

Churchman CW. 1971. The design of inquiring systems: basic concepts of systems and organizations. London: Bencis Books.

Cockett R. 2006. South Africa's challenge. The Economist. [Online] Available from: www.economist.com [Accessed: 13/04/2006].

Davel R \& Snyman MMM. 2005. Influence of corporate culture on the use of knowledge management technologies [Online] Available from: www.sajim.co.za [Accessed: 04/11/2005].

Davenport TH \& Prusak L. 1998. Working knowledge: how organisations manage what they know. Boston: Harvard Business School Press.

Domingues JM, Laverde AM, Lisarralde O \& Arregui B. 2003. An overview of empirical reports about Knowledge Management. San Sebastian: $3^{\text {rd }}$ European Knowledge Management Summer School.

Drucker PF. 1995. Managing in a Time of Great Change. New York: Truman Tally. 
Du Plessis T \& Du Toit ASA. 2005. Survey of information and knowledge management in South African law firms [Online] Available from: www.sajim.co.za [Accessed: 27/04/2005].

Gichuru P \& Tobin PKJ. 2004. Problems encountered diffusing tacit knowledge at Eli Lilly SA [Online] Available from: www.sajim.co.za [Accessed: 27/04/2005].

Grant RM. 1991. Prospering in dynamically-competitive environments: organisational capability as knowledge integration. Organisation Science, 7(4):375-387.

Hanfmann E, Vakar G \& Vygotsky LS. 1962. Thought and Language. Cambridge: MIT Press.

Huseman RC \& Goodman J. 1999. Leading with knowledge: the nature of competition in the $21^{\text {st }}$ Century. London: Sage Publications.

Intronas LD. 1992. Towards a theory of management information. Unpublished doctoral thesis. Pretoria: University of Pretoria.

Jaques E \& Clement SD. 1991. Executive leadership - a practical guide to managing complexity. Arlington: Carson Hall.

Kay S. 2003. Benchmarking knowledge management in US and UK law firms [Online] Available from: www.llrx.com/features/benchmarking.htm [Accessed: 19/03/2004].

Khandelwal VK \& Gottschalk P. 2003. A knowledge management survey of Australian law firms. Sydney: University of Western Sydney.

Kok JA. 2003. Role of leadership in the management of corporate knowledge [Online] Available from: www.sajim.co.za [Accessed: 27/04/2005].

Kruger CJ \& Snyman MMM. 2005a. Formulation of a strategic knowledge management maturity model [Online] Available from: www.sajim.co.za [Accessed: 04/11/2005].

Kruger CJ \& Snyman MMM. 2005b. Determining the value of knowledge management. Mousaion, 23(2):165-179.

Lank E. 1997. Leveraging invisible assets: the human factor. Long-range Planning, 30(12):406-412.

Lawson J. 2000. Avoiding the pitfalls of duplication. Knowledge Management, 2(1):14-20.

Ndlela LT \& Du Toit ASA. 2000. Corporate culture as a foundation for successful knowledge management [Online] Available from: www.sajim.co.za [Accessed: 27/04/2005].

OECD (Organisation for Economic Co-operation and Development). 1996. The Knowledge-based economy. Paris: OECD.

Perkins D. 2001. The Eureka Effect. New York: Norton.

Platt N. 1997. Knowledge Management: can it exist in a law office? [Online] Available from: www.llrx.com/features/km.htm [Accessed: 19/03/2004].

Rumizen MC. 2002. The complete idiot's guide to knowledge management. Madison: CWL Publishing Enterprises.

Spencer JC. 1996. Making knowledge: the basis of a dynamic theory of the firm. Strategic Management Journal, 17(1):45-62.

Storey J \& Barnett E. 2000. Knowledge Management initiatives: learning from failure. Journal of Knowledge Management, 4(2):145-156. 
Tobin PKJ \& Franze MH. 2005. Organisational structure and knowledge management: a case study. Mousaion, 23(2):149-164.

Tobin PKJ \& Snyman MMM. 2004. World-class knowledge management: a proposed framework [Online] Available from: www.sajim.co.za [Accessed: 27/04/2005].

Tobin PKJ \& Volavsek P. 2006. Knowledge management measurement in South African organisations. Mousaion, 24(1).

Van den Berg H \& Snyman MMM. 2003. Managing tacit knowledge in the corporate environment: communities of practice [Online] Available from: www.sajim.co.za [Accessed: 27/04/2005]. 